\title{
The Pragmatics of Connectives in English and Igala
}

\author{
Abraham Sunday Unubi \\ Department of Linguistics and Communication Studies, University of Port Harcourt, PMB 5323, Choba, Port \\ Harcourt, Nigeria
}

Abstract

This paper examined the pragmatics of connectives in English and Igala. The article revealed that pragmatic connectives usually express relations between speech acts. That is, it essentially handles the issue of how connectives perform their linking functions contextually or pragmatically to encode meaning in a language. When two propositions are linked by a connective, whether uttered by an interlocutor or between an interlocutor and a listener, pragmatics plays a pivotal role in influencing their meanings to be something different from what they should be denotatively. Data collection for this research was generated exclusively from secondary sources, which was drawn mainly from the existing material on pragmatic connectives in both languages. Thus, the pragmatic implications of propositions linked by connectives were clearly presented and analysed concurrently. The data comprised five utterances of both English and Igala, which also contained five connectives, namely: àmâ 'but', todúlé 'so', tyáji 'unless/until/till', àbèkí 'or' and îteun 'if' were selected, presented and analysed. The English data was labelled $\boldsymbol{A}$ while the one on Igala was marked $\boldsymbol{B}$. The major result of the study indicated that connectives actually have pragmatic value, especially when linked with two propositions in both languages.

Key words: pragmatics, connectives, English, Igala.

DOI: $10.7176 /$ RHSS/9-13-06

Publication date:July $31^{\text {st }} 2019$

\section{Introduction}

Pragmatic connectives usually express relations between speech acts. Normally, speech acts do not come alone. They actually occur in ordered sequences as accomplished by one speaker or subsequent speakers, e.g. in the course of a conversation. In other words, a sound analysis of speech acts, which is a central task in pragmatics, to some extent, cannot be carried out without previous understanding of the notion of an act or action. As a matter of fact, a serious linguistic pragmatics should not only account for speech acts but also for relations between speech acts and the ways these relations are expressed in the sentences and texts used to perform such speech act sequences. Particularly then, our main concern in this research is to investigate how these relations are expressed by various connectives in both English and Igala languages.

\subsection{Brief Linguistic Information on English and Igala}

\subsubsection{English}

Wilton (2001) as cited in Unubi (2018:6) states that the English language belongs to the West Germanic branch of the Indo-European family of languages. This broad family includes most of the European languages spoken today. The Indo-European family includes several major branches, as follows:

- Latin and the modern Romance languages;

- The Germanic languages;

- The Indo-Iranian languages, including Hindi and Sanskrit;

- The Slavic languages;

- The Baltic languages of Latvian and Lithuanian;

- The Celtic languages; and

- Greek

The influence of the original Indo-European language, designated proto-Indo-European can be seen today, even though no written record of it exists. The word father, for example, is vater in German, pater in Latin, and pitir in Sanskrit. These words are all cognates, similar words in different languages that share the same root. From the foregoing, it is clear that the English language has its origin in north-western Germany, from where it was brought to England by the Anglo-Saxons. At the time this happened, approximately 1,500 - 1,600 years ago, English was very different from what it is today, in grammar, vocabulary and pronunciation. This difference is indicated by the use of the expression 'Old English' (or, sometimes, 'Anglo-Saxon') to refer to the earlier form of the language.

\subsubsection{Igala}

Genetically and typologically, Negedu (2003) as cited in Unubi and Yusuf (2017) notes that Igala as one of the African languages, belongs to the Kwa subgroup of the Niger Congo language family. The Niger Congo languages constitute one of the world's major language families and Africa's largest in terms of geographical area and number of speakers. Igala is further classified as a language of the Yoruboid branch of the Defoid 
family. The Defoid languages constitute a branch of the present Benue Congo language family. It comprises the Yoruba, the Igala and the Itsekiri groups of south-western Nigeria. In a similar submission, Unubi and Yusuf (2017:413) quote Capo (1985) saying that the term Yoruboid is used to refer to a compact language complex including Yoruba, Itsekiri and Igala. So, the Yoruboid complex is a major branch of the Yoruboid-Akokoid unit of the Benue-Congo division of the Volta-Congo languages. The Akokoid languages are Niger-Congo languages spoken southwest of the Niger-Benue Confluence in Ondo State, Akoko North Local Government Area and Kwara State as well as Kogi State of the North Central Nigeria.

\section{Statement of the Research Problem}

Indubitably, studies on Pragmatics of connectives in English and Igala seem to be rare at the moment. Hitherto, reference or allusion has been made to pragmatics and conjunctions or linkers or joinders, e.g. Egbunu (2014), Unubi (2015) as well as Unubi (2018) but researches on pragmatic connectives, particularly in Igala, as it appears, are yet to be conducted. Obviously, this in itself is a research or knowledge gap as far as linguistics is concerned, which the present study is poised to fill. And in an attempt to do this, the researcher has made a concerted effort to offer an analytic explanation of how two propositions could be linked by a connective to encode meaning contextually or pragmatically in both languages.

\section{Literature Review}

Under this section, our review will capture relevant concepts that constitute the topic or title of this research; namely: pragmatics and connectives, in addition to previous empirical works done by other scholars that are related to the current study.

\subsection{Conceptual Review}

As advanced by Liu (2003:1), pragmatics is a relatively late comer in linguistics, and that it enters the linguistic scene at the end of the 1970s. He states that pragmatics caters for a special part or aspect of meaning that semantics overlooks or fails to handle. To this end, he defines pragmatics as a sub-branch of linguistics that deals with how language users mean by different signs in different speech events or contexts. He adds that pragmatics is concerned about those dynamic or contextual or non-conventional meanings of words and sentences articulated by language users. In a similar view, Mey (2001:6) says that a truly pragmatic consideration has to deal with the language users in their social contexts. Consequently, pragmatics studies the use of language in human communication as determined by the conditions of society. In the introductory section of their edited work, Horn and Ward (2006:xi) define pragmatics as the study of those context-dependent aspects of meaning which are systematically abstracted away from in the construction of content or logical form. According to Byram \& Hu (2013:548), pragmatics is a subfield of linguistics developed in the late 1970s, which studies how people do things with words. Whereas 'doing things' is tantamount to communication, 'with words' denotes the use of linguistic resources available for 'doing things' or communication. Put another way, pragmatics studies how people comprehend and produce verbal acts or utterances in concrete speech situations which are usually conversations. Furthermore, Yule (1996:127) explains that when we read or hear pieces of language, we normally try to understand not only what the words mean, but what the speaker or writer of those words intended to convey. The study of 'intended speaker meaning' is called pragmatics. In other words, pragmatics is the study of 'invisible' meaning, or how we recognise what is meant even when it is not actually said or written, adding that for this to happen, speakers and writers must be able to depend on a lot of shared assumptions and expectations. Moreover, Akmajian \& Demers et al. (2001:261) declare that the term pragmatics covers the study of language use, and in particular the study of linguistic communication, in relation to language structure and context of utterance. For instance, pragmatics must identify central uses of language, it must specify the conditions for linguistic expressions (words, phrases, sentences, discourse) to be used in those ways, and it must seek to uncover general principles of language use.

Relations between propositions or facts are typically expressed by a set of expressions from various syntactic categories, which are called connectives. Obviously, connectives are words that link or connect ideas within an utterance or a write-up. Consequently, they can be used within sentences to link two or more sentences together, and they can also be used to link ideas in separate sentences and paragraphs. On this note, Crystal (1991:102) states that the term connective is used in the grammatical classification of words to characterise words or morphemes whose function is primarily to link linguistic units at any level. Furthermore, Gerlach \& Sprenger (2000:193) express that connectives are a means of expressing the argumentative and logical structure of the speaker's opinions by linking propositions. Such relations between propositions are classified into several categories such as inferential, temporal, causal linkages, etc. In a similar view, Maat \& Sanders (2006:33) define connectives as one-word items or fixed combinations that express the relation between clauses, sentences or utterances in the discourse of a particular speaker. Speaking further, they state that more generally, a connective indicates how its host's utterance is relevant to the context. In addition, Mauri \& Auwera (2012:377) submit that 
by connectives we mean a linking device establishing a given relation between two clauses or phrases. In a more appropriate manner, Heeman and Allen (1999) as cited in Salih (2014:16) declare that connectives are "devices which are conjectured to give the hearer information about the discourse structure; they aid the hearer to understand the relationship between the present or new speech and what was previously said". They further reveal that connectives have various pragmatic functions in discourse such as holding a turn, signalling an interruption in the discourse structure, signalling an acknowledgement or acceptance, stalling for time or to signal a speech repair. Indeed, this definition is extremely relevant to the present study because its focus is the pragmatic function of connectives. It is in view of this that Moeschler (1989:323) pronounces that a pragmatic connective is any lexical item of a particular natural language which connects two (or more) propositions realised in utterances, in a non-truth-functional manner.

\subsubsection{Types of Connectives}

There are differing views among language scholars on the types of connectives. For example, scholars such as Arthur (1996), Baskervill and Sewell (1896), Lester (1990) and Eckhard-Black (1992) divide connectives into two classes - coordinating and subordinating. But traditionally, there are three basic types of connectives. They include: (i) coordinating connectives, as reported by Unubi (2018:26), are used to connect words, phrases and clauses. Aside this, coordinating connectives are used to connect the elements of sentences that have equal levels. This means that they connect two sentences that do not rely on each other for meaning. Coordinating connectives further subdivide into three, which are additive e.g. 'and'; alternative e.g. 'or'; and adversative e.g. 'but', (ii) subordinating connectives are used to connect subordinate clauses with the principal clauses in a complex sentence. Principal or main clauses can stand alone and do not depend on subordinate clauses while subordinate or dependent clauses cannot. Therefore, dependent or subordinate clauses depend on the principal or main clauses for complete sense or meaning. Subordinating connectives are subdivided into the following: temporal e.g. 'after', 'before'; causal e.g. 'because', 'for', 'so', 'that'; adversative e.g. 'yet', 'however', 'nevertheless', 'though/although'; condition e.g. 'if', 'unless'; comparison e.g. 'than'; time e.g. 'when'; place e.g. 'where', and (iii) correlative connectives are link words that comprise of two parts which are used to give emphasis to the combinations of two structures that are balanced. Often time, correlative connectives are regarded as team connectives because they are used in pairs. They derive their name from the fact that they work together (co-) and relate one sentence element to another. Correlative connectives are subdivided into two, and they include cumulative e.g. 'both ... and', 'neither ... nor'; and alternative e.g. 'whether ... or', and 'though ... yet'.

\subsection{Empirical Review}

Over time, a good number of studies on pragmatics and connectives that are related to the present research have been embarked upon by scholars in both English and Linguistics. Some of them include the following:

Dijk (1979) embarked on a study entitled Pragmatic Connectives. In the article, the pragmatic function of connectives was discussed. Pragmatic connectives usually express relations between speech acts. According to the researcher, speech acts do not normally come alone. They may occur in ordered sequences of speech acts accomplished by one speaker or by subsequent speakers, e.g. in the course of a conversation. Speech acts must also satisfy a number of constraints. One of the obvious tasks for an extension of a theory of speech acts within linguistic pragmatics, then, is the formulation of these constraints. The study concluded that most of the pragmatic connectives may be assigned a function in terms of the satisfaction of conditions for preceding or following speech acts: a speaker will add, check, question, attack, etc. one of these conditions, or even the speech act as a whole. Variations may be stylistic, rhetorical and conversational: some forms will be more polite, more aggressive, etc. than others. Finally, there is a main, super-ordinate speech act, which is modified by the subordinate speech act introduced by a pragmatic connective. Future research will have to focus on the further textual or conversational details of the strategies determining the use of the various pragmatic connectives.

In the same vein, Moeschler (1989) conducted a study titled Pragmatic Connectives, Argumentative Coherence and Relevance. This study was poised to examine the notion of pragmatic connectives and its relations to argumentative, discursive and interpretive phenomena. In this research, three approaches to pragmatic connectives were presented: (i) argumentation theory, which implies a conception of pragmatics integrated within semantics, and a specific type of argumentative rules; (ii) discourse structure theory, which associates a function in the structuring of discourse sequences to pragmatic connectives; and (3) relevance theory, which constitutes a cognitive pragmatic theory, in which no specific principle is associated to linguistic items. According to the researcher, the notion of pragmatic connectives became popular in the domain of semantic and pragmatic studies in French linguistics around 1980, because it appeared as a basic argument for a model of semantics which could integrate pragmatic properties of utterances. Besides, the researcher made a clear-cut distinction between logical and non-logical or pragmatic connectives, showed the discursive properties of these connectives, and indicated their role in the inferential process attached to the interpretation of connected utterances. Lastly, the study closed by distinguishing between two categories of implicit import: on one hand, there are the assumptions that the hearer recovers as conclusions of the deduction, that is, the implicated 
conclusions; while on the other, there are the contextual assumptions that the hearer supplies as premises in order to derive these conclusions.

Furthermore, Salih (2014) carried out a research entitled A Comparative Study of English and Kurdish Connectives in Newspaper Opinion Articles. The research investigated English and Kurdish connectives which signal conjunctive relations in online newspaper opinion articles. As its framework, the study utilised the Hallidayan framework of connectives in the light of the principles of Relevance Theory as established by Sperber and Wilson (1995). That is, connectives are considered in terms of their procedural meanings, i.e., the different interpretations they signal within different contexts, rather than their conceptual meanings. The methods of data gathering for the study underwent four main stages. In each stage there were selection criteria which guided the choices to include particular examples of a particular text type (newspapers), genre (opinion articles), linguistic feature (connectives) and participants (translators who have been commissioned to translate all the connectives under investigation from English into Kurdish and vice versa). The study found out that the Halliday and Hasan's (1976) classification of conjunctive relations and connectives needs to be modified, in order to lay out a clearer classification of English connectives that could account for their essential characteristics and properties. This modified classification would also help classify Kurdish connectives with greater accuracy.

Lastly, Unubi (2016) executed a study titled Pragmatics: Historical Development, Scope and Subject Matter or Object of Study. According to the researcher, history is an interminable interaction between the present and the past, and it sheds the light of the past upon the future, hence the need to know the historical origin of pragmatics. As a matter of fact, knowing the historical development of pragmatics as a language course, brought about by the efforts of early scholars to popularise it as it is today, as well as their concerted attempts to broaden its scope, as seen in this paper, is very crucial to both students and scholars of linguistics. Although pragmatics is a relatively new branch of linguistics, its historical development dates back to ancient Greek and Roman academic works where the terms pragmaticus is found in late Latin and pragmaticos in Greek, both mean being pragmatical. The scope of pragmatics, according to this research, as extended by Morris included psychological, biological and sociological phenomena which occur in the functioning of signs. Today, this will cover other areas of study such as psycholinguistics, sociolinguistics, neurolinguistics. In addition, pragmatic study has thrown some light on the study of literature, especially figures of speech such as hyperbole, personification, and euphemism and so on, giving rise to literary pragmatics. Similarly, the application of pragmatics to computational linguistics has also developed into computational pragmatics. As noted by the researcher, the subject matter or the object of study of pragmatics is context. Context allows us to use our linguistic resources to the utmost, without having to spell out all the tedious details every time we use a particular construction. Context is dynamic, and not a static concept. That context is the subject matter of pragmatics underscores its overall importance and as such, it is never an overstatement to say that context is pragmatics and pragmatics is context.

\section{Theoretical Framework}

This research is hinged on the pragmatic theory of literature, propounded by Pratt in 1977. Pratt (1977) as cited in Hussein (2006:19) declares that literary works, similar to all of our communicative activities, are contextbound. Literature in itself then is a context of speech. Therefore, the way people produce and understand literary works depends "enormously on unspoken, culturally-shared knowledge of the rules, conventions and expectations that are in play when language is used in that context". Hence, as definitions of thanking, explaining or persuading must include the context of unspoken information on which the participants are relying, so must a definition of literature. In view of this, he states further that speech act theory (SAT) whose main role is in every day conversations, is extremely important in this sense of literature in addition to offering interpretation to utterances in their surface grammatical features, it also discusses these utterances in terms of the context in which they are made, the intentions, attitudes, the relationships between participants and generally in terms of the conventions and the unspoken rules that play an important role when such utterances are made and received. Therefore, the real reader of a literary work is part of the context, and thus part of the interpretations of the utterance. This is due to the fact that a real reader receives the intention of the real author who wants to achieve a certain perlocutionary effect on a certain socio-cultural context.

A careful consideration of the above theory shows its relevance to the present research. As a matter of fact, this paper is a literary work. It is a pragmatic literature that offers pragmatic interpretation to utterances or clauses or sentences that are joined with connectives in Igala. This interpretation goes from the surface or denotative meaning of such utterances to their pragmatic significance as far as meaning is concerned. Therefore, this study, being a work of literature, is appropriate for the pragmatic theory of literature.

\section{Methodology}

In the current study, we shall adopt the secondary sources as the major source of data collection. This means that we will make use of extant material, particularly those on pragmatics as sources of our data. Obviously, one 
exercise that cannot be ruled out in this research is that of translation, as far as the data on the Igala is concerned. This is necessary because there have been little researches or none at all hitherto on pragmatics in the Igala language. Consequent upon this, the researcher will make painstaking effort at reading and translating deftly into Igala the existing material on pragmatic connectives written either in English or other languages of the world as a way of ensuring that this research fits into pragmatics adequately, while the English data will remain in English. This way, the English data will be labelled A while the one on the Igala will be B. And this will be meticulously guided by the insight, awareness or intuition of the researcher, being a native speaker of Igala. Moreover, selected to be presented and analysed as data for this study are five utterances of both English and Igala containing five connectives, namely: àmâ 'but', todúlé 'so', tfájí 'unless/until/till', àbèkí 'or' and ítfeun 'if' will be presented and analysed concurrently with a view to helping the reader understand the work properly. The Igala type of the utterances and connectives are transcribed and tone-marked to provide easy pronunciation for the readership. Also, since pragmatic connectives are not new, our analysis tends towards the Igala version. And the Igala version of the data will be presented and analysed by utilising the interlinear word-by-word alignment gloss of the Leipzig Glossing Rule, in conjunction with English as the metalanguage.

\section{Presentation of Data/Analysis or Discussion}

As earlier mentioned, our data is presented concurrently along with the analysis or discussion. This is so done for easy comprehension of this study. Both the data and their analyses are presented under this section. Before we have this done, however, recall that we have already mentioned in our introduction that pragmatic connectives usually express relations between speech acts. Speech acts in themselves do not come alone. They may occur in ordered sequences as accomplished by one speaker or subsequent speakers, e.g. in the course of a conversation. Our major preoccupation here is to investigate how these relations are expressed by various connectives in the Igala language as shown below:

1. (A) John was ill but he came to the meeting.

(B) ola bo ywú Ódzíma ý, àmâ ì wa údzedzu.

body well him Ojima NEG CONN he come (PST) meeting

Ojima was not well but he came to the meeting.

Note that being ill or sick is one of the cogent reasons for not attending meetings, and hence, our general knowledge about meetings and about Ojima's illness would generate certain expectations of which the speaker would assume that they are shared by the hearer which requires the use of contrastive àmâ 'but' in the language. Aside this, notice also that in (1) above, àmâ 'but' essentially relates two events that are somehow incompatible in the sense that the second fact is an 'exception' to the normal consequences of the first fact. That is, one who is ill should not be expected in a meeting. Indeed, this is the unexpected consequence of àmâ 'but'.

In addition to the above (àmâ 'but'), one of the best known pragmatic connectives is todúlé 'so', especially when linked with the semantic todúlé 'so', it denotes a consequence with respect to a cause or reason expressed in a previous clause or sentence. Consider this example:

2. (A) I was sick, so I stayed indoors.

(B) ola bo ymi ý, todúlé ú dufù ý.

body well me NEG CONN I go (PST) NEG

I was not well, so I stayed indoors.

Notice that in (2) above, the pragmatic todúlé 'so' links two speech acts of which the second functions as 'conclusion' with respect to the first speech act. The pragmatic nature of this connective is based on the fact that 'drawing a conclusion' is taken to be an act. Clearly, this pragmatic function may be based on the semantic relation of cause-consequence, as mentioned early on. We have something similar to this in logical languages: on the one hand we have a conditional (e. g. strict implication) linking propositions, and on the other hand we have rules of inference defining valid proofs (derivability). Thus, if $p$ implies $q$, then we may also say that $p$ is true, and $q$ may be derived from it. In other words, if certain information has been provided, the communicative context allows a speaker to perform the next speech act. This way of marking conclusions with respect to the communicative context is also typical in conversations where todúlé 'so' indicates that the speaker draws a conclusion from the speech act performed either by the previous or the same speaker.

3. (A) You will not eat today, unless you do this work.

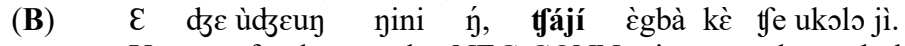

You eat food today NEG CONN time you do work this

You won't eat today, unless you do this work.

Pragmatically, the foremost issue to be noted here is that (3) is stated, at least rhetorically, to hold only under specific condition (i.e. to eat, the interlocutor must do the work). In other words, (3) is restricted to a situation in 
which some condition must be satisfied. It is clear here that the pragmatic connective tfájí 'unless' expresses a relation between speech acts, which must be accomplished by one speaker or subsequent speaker(s) in the course of a conversation. In most cases, tfájí 'unless' pertains to the often rhetorical, or fulfilling of appropriateness conditions of a neighbouring, mostly preceding speech acts.

4. (A) Won't you eat? Or are you not hungry?

(B) $\varepsilon$ dze ùdzeun ń? Àbèki ebi kpa $\varepsilon$ ń?

You eat food NEG CONN hunger kill you NEG

Won't you eat food? Or you are not hungry?

The use of pragmatic àbèkí 'or' is clearly unique. This is because it requires that two facts are alternatives in two possible worlds (unknown to the speaker). It is obvious that pragmatic àbèkí 'or' typically introduces questions. In (4) above, the function of these questions is to check, make sure, correct, etc. conditions of a previous speech act of the same speaker. That is, a speaker may perform a request, an order, a promise, etc. but may at the same time wonder whether important conditions are satisfied for that act to be appropriate in that context. Having uttered (4) above, the speaker may have some doubt about the knowledge of the hearer and therefore 'corrects' his assertion by asking whether the presupposed knowledge is present. The above speech act, introduced with àbèkí 'or' then requires information (hence the fact that they are often questions) to check the necessary presuppositions. In considering the various pragmatic features of àbèkí 'or', we could as well use the notion of 'ascertaining' to capture its pragmatic functions.

5. (A) If you are hungry, there is food in the pot.

(B) Ítfeun ki ebi ákpa $\varepsilon$, ùdł̧un d $\varepsilon$ efu ùtfà $l \varepsilon$. CONN BE hunger kill you food BE inside pot ART

If you are hungry, there is food in the pot.

In (5) above, if we take the second clause as an indirect permission ('You may take ...'), the first clause establishes the situation in which such permission would be relevant ('In case you are hungry'). In that reading, the pragmatic ítfeun 'if' is a typical conditional for speech acts: it specifies the conditions of a context unknown to the speaker under which a speech act should count. Notice that the ítfeun 'if'-conditional connective in the above sentence does not merely introduce a restriction but at the same time operates as a pragmatic connective linking a promise with a specification of the promise. Hence, the ítfeun 'if'-clause does not pertain to the speech acts but to the acts referred to in the main clause, viz as a necessary or sufficient condition for these acts.

\section{Conclusion}

This work has treated the pragmatics of connectives in English and Igala, though not exhaustive. Nevertheless, this research, which has attempted both at characterising and revealing clearly the pragmatic status of connectives, particularly in the Igala language, is the first attempt as far as the pragmatic connectives are concerned. It is necessary to point out here that from the data presented and analysed, this work has evidently established the pragmatic value of connectives in the languages under focus. In addition, the concurrent presentation and analysis of the data has helped the readership in no small measure to understand the nitty-gritty of this work. This study is never an attempt to force English on Igala but to try to see naturally if pragmatic connectives exist in the language.

\section{Contribution to Knowledge}

Without doubt, this study which attempted to characterise pragmatic connectives in English and Igala, and which had also revealed that connectives actually have pragmatic value, especially when linked with two propositions in both languages, could be used as an invaluable reference material to provoke more studies among language scholars both locally and internationally leading to knowledge expansion. This implies that both undergraduate and graduate students of English and Linguistics could use this work as a guide to carry out similar studies in English and one indigenous Nigerian language or in indigenous languages of Nigeria and other languages of the world in their projects and dissertations. Apart from this, making this research available in the field of Linguistics as an addition to the existing body or collection of knowledge is a valuable and positive contribution.

\section{Recommendations for Further Studies}

As mentioned earlier on, no research could be considered exhaustive anywhere in the world. So, the five utterances containing five connectives selected, presented and analysed in this study should not be seen as deficient or inadequate but as an endeavour. Consequently, there is need to carry out more studies on the pragmatics of connectives in indigenous languages of Nigeria. Indeed, undergraduate, graduate students and scholars in language and linguistics could use this study as a guide to carry out or explore other topics such as: pragmatic connectives: a reality in (any language), pragmatic connectives as used by football fans, the pragmatics of connectives in the speech of sports commentators, analysing pragmatic connectives in (any 
language), the use of pragmatic connectives among radio newscasters, and so forth. So, we can see that pragmatic connectives constitute a study or knowledge area waiting for language scholars to explore.

\section{References}

Akmajian, A.R.A., Demers, Farmer, A.K., and Harnish, R.M. (2001). Linguistics: An introduction to language and Communication. $5^{\text {th }}$ (ed.). Cambridge. UK MIT Press.

Byram, M. and Hu, A. (2013). Routledge encyclopedia of language teaching and learning. In M. Byram and A. $\mathrm{Hu}$ (eds.). $2^{\text {nd }}$ (edn.). Routlegde: Taylor \& Francis Group.

Crystal, D. (1991). A dictionary of linguistics and phonetics. Oxford: Blackwell Publishers.

Dijk, T.A.V. (1979). Pragmatic connectives. Journal of Pragmatics. 3, 447 - 456. North-Holland Publishing Company.

Egbunu, F.E. (2014). Language problem in African philosophy: The Igala case. Journal of Educational Social Research. 4, 363 - 371. Rome-Italy: MCSER Publishing.

Gerlach, M. and Sprenger, M. (2000). Semantic interpretation of pragmatic clues: Connectives, modal verbs, and indirect speech acts. University of Hamburg. [Online] Available: http://www.aclweb.org/anthology/C88-1039. 22/8/2018.

Horn, L.R. and Ward, G. (2006). The handbook of pragmatics. In L. R. Horn and G. Ward (eds.). Blackwell Publishing.

Hussein, M. K. (2006). The pragmatic theory of literature. Journal of Al-Qadisiya University. 9, $1 \& 2,19-29$. [Online] Available: $\quad$ file:///C:/Users/user/Downloads/thepragmatictheoryofliterature\%20(1).pdf. $28 / 8 / 2018$.

Liu, S. (2003). New perspectives of pragmatics. College of Foreign Studies, Guangxi Normal University. [Online] Available: http://www.gxnu.edu.cn/Personal/szliu/pragmatics.html 22/8/2018.

Maat, H.P. and Sanders, T. (2006). Connectives in text. Universiteit Utrecht, Utrecht, Netherlands. Esevier.

Mauri, C. and Auwera, J.V.D. (2012). Connectives. In K. Allen and K. M. Jaszczolt (eds.). The Cambridge Handbook of Pragmatics. Cambridge University Press.

Mey, J.L. (2001). Pragmatics: An introduction. $2^{\text {nd }}$ (ed.). Blackwell Publishing.

Moeschler, J. (1989). Pragmatic connectives, argumentative coherence and relevance. Université de Genève, Suisse. [Online] Available: file://C:/Users/user/Downloads/Pragmatic connectives argumentative coherence and pdf. $24 / 8 / 2018$

Negedu, I.A. (2003). The Igala traditional religious belief systems: Between monotheism and polytheism. Ogirisi: A New Journal of African Studies. 10, 116 - 129.

Salih, R.R. (2014). A comparative study of English and Kurdish connectives in newspaper opinion articles. Ph.D Thesis. School of English, University of Leicester. [Online] Available: https://lra.le.ac.uk/bitstream/2381/29255/1/2014SALIHRRPHD.pdf. 24/8/2018.

Unubi, S.A. (2018). A contrastive analysis of the use of conjunctions in English and Igala. Lambert: LAP Lambert Academic Publishing.

Unubi, S.A. (2016). Pragmatics: Historical development, scope and subject matter or object of study. International Journal of Advanced Multidisciplinary Research (IJAMR). 3, 12, 37 - 43.

Yule, G. 1996. The study of language. $2^{\text {nd }}$ (ed.). Cambridge: Cambridge University Press. 